\title{
Amyloidosis of the Larynx: A Clinicopathologic Study of 11 Cases
}

Lester D.R. Thompson, M.D., Gregory A. Derringer, M.D., Bruce M. Wenig, M.D.

Departments of Endocrine and Otorhinolaryngic-Head \& Neck Pathology (LDRT, BMW) and

Hematopathology (GAD), Armed Forces Institute of Pathology, Washington, D.C.

Laryngeal amyloidosis (LA) is uncommon and poorly understood, with limited long-term clinicopathologic and immunophenotypic studies in the literature. Eleven cases of LA were retrieved from the files of the Otorhinolaryngic-Head \& Neck Tumor Registry from 1953 to 1990 . The histology, histochemistry, immunohistochemistry, and follow-up were reviewed. All patients (three women and eight men) presented with hoarseness at an average age of 37.8 years. The lesions, polypoid or granular, measured an average of $1.6 \mathrm{~cm}$ and involved the true vocal cords only $(n=4)$, false vocal cord only $(n=1)$, or were transglottic $(n=6)$. An acellular, amorphous, eosinophilic material was present in the stroma, often accentuated around vessels and seromucous glands, which reacted positively with Congo red. A sparse lymphoplasmacytic infiltrate was present in all cases that demonstrated light chain restriction by immunohistochemistry in three cases $(\kappa=2, \lambda=1)$. Serum and urine electrophoreses were negative in all patients. Treatment was limited to surgical excision, including a single laryngectomy. Six patients manifested either recurrent and/or multifocal/systemic disease: two patients with light chain restriction were dead with recurrent disease (mean, 11.1 years); two patients were dead with no evidence of disease (mean, 31.7 years); and two patients were alive, one with light chain restriction and recurrent and multifocal disease (41.6 years) and one with no evidence of disease after a single recurrence (43.4 years). The remaining five patients were either alive or had died with no

Copyright (C) 2000 by The United States and Canadian Academy of Pathology, Inc.

VOL. 13, NO. 5, P. 528, 2000 Printed in the U.S.A.

Date of acceptance: November 2, 1999.

The opinions and assertions contained herein are the private views of the authors and are not to be construed as official or as reflecting the views of the Department of Defense.

Presented at the 88th Annual Meeting of the United States and Canadian Academy of Pathology, San Francisco, California, March 20-26, 1999.

Address reprint requests to: Lester D.R. Thompson, M.D., Department of Endocrine and Otorhinolaryngic-Head \& Neck Pathology, Building 54, Room G066-11, Armed Forces Institute of Pathology, 6825 16th Street, N.W., Washington, DC 20306-6000; e-mail: thompsonl@afip.osd.mil; fax: 202-782-3130. evidence of disease an average of 32.4 years after diagnosis. No patient developed multiple myeloma or an overt B-cell lymphoma.

$\mathrm{LA}$ is an uncommon indolent lesion that may be associated with multifocal disease (local or systemic). The presence of an associated monoclonal lymphoplasmacytic infiltrate and recurrent/multifocal disease in the respiratory or gastrointestinal tract of a few cases and the lack of development of a systemic plasma cell dyscrasia or overt systemic B-cell malignancy suggest that some LA may be the result of an immunocyte dyscrasia or tumor of mucosaassociated lymphoid tissue.

KEY WORDS: Amyloid tumor, Amyloidoma, Amyloidosis, Immunohistochemistry, Larynx, Localized, Mucosa-associated lymphoid tissue.

Mod Pathol 2000;13(5):528-535

Amyloid is a heterogeneous family of extracellular proteinaceous deposits with characteristic microscopic, histochemical, and ultrastructural features. Amyloid in the larynx can be identified as subepithelial extracellular deposits of acellular, homogeneous and amorphous, eosinophilic material displaying apple-green birefringence with polarized light when stained with Congo red or that is metachromatic with crystal violet or methyl violet (1-9).

Deposits of amyloid in the larynx are rare, accounting for between 0.2 and $1.2 \%$ of benign tumors of the larynx (9-14). They usually present as localized disease but may be a part of systemic disease, the result of a familial condition, a primary disorder, or secondary to an underlying disease or tumor proliferation $(1,4,7,9,15,16)$. Different sources of amyloidosis are recognized and include (1) immunoglobulin light chains, (2) amyloid A in reactive amyloidosis, (3) transthyretin type in familial or senile amyloid, and (4) hemodialysisassociated amyloid $(2,3,5-7,13,16)$. The biochemical and immunophenotype of laryngeal amyloid has been described $(1,7,16,17)$, but the long-term natural history of laryngeal amyloidosis LA remains clouded $(18,19)$. Therefore, for a better under- 
standing of laryngeal amyloid, we reviewed the clinical, pathologic, histochemical, and immunohistochemical properties of laryngeal amyloid and correlated these findings with the patient outcome.

\section{MATERIALS AND METHODS}

Eleven cases of laryngeal amyloid for which there was clinical follow-up were selected from the files of the Otorhinolaryngic-Head and Neck Tumor Registry at the Armed Forces Institute of Pathology from the years 1953 to 1990 in a review of 5041 $(0.2 \%)$ benign or malignant primary laryngeal tumors. We used a cutoff of 1990 to ensure at least 10 years of follow-up.

Armed Forces Institute of Pathology materials were supplemented by a review of the patients' demographics, symptoms at presentation, laboratory results, surgical pathology, and operative reports and by written questionnaires or oral communication with the treating physician(s) or patient. Follow-up data included information regarding the development of systemic or multifocal disease, extent of disease, serum or urine electrophoretic studies, bone marrow results, the specific treatment modalities used, and the current status of the disease and the patient.

Hematoxylin and eosin-stained slides for all cases were reviewed to confirm that established histologic criteria for amyloid were met $(4,9,13)$. Congo red and methyl violet stains were performed on 10 cases. Immunophenotypic analysis was performed on 10 cases using the standardized avidinbiotin method of Hsu et al. (20) with 4 - $\mu$-thick formalin-fixed, paraffin-embedded sections. The antibody panel included $\kappa$ (mouse monoclonal; Dako, Carpinteria, CA; 1:1000), $\lambda$ (mouse monoclonal; Dako; 1:1000), CD20 (L26, mouse monoclonal; Dako; 1:200), CD3 (rabbit polyclonal; Dako; 1:500), and CD45RB (LCA, mouse monoclonal; Dako; 1:160). Predigestion was performed for 3 min with 0.05\% Protease VIII (Sigma Chemical Co., St. Louis, $\mathrm{MO}$ ) in a $0.1 \mathrm{~m}$ phosphate buffer at a $\mathrm{pH}$ of 7.8 at $37^{\circ}$ $\mathrm{C}$ for the $\kappa, \lambda$, and CD3. Appropriate positive and negative (serum) controls were used throughout.

\section{RESULTS}

\section{Clinical Findings}

The patients included eight men and three women, with a male:female ratio of 2.7:1. Their ages ranged from 24 to 65 years, with a mean age at presentation of 37.8 years (median, 36 years). Eight patients were white, one was African American, and the race was unknown in two patients.

Progressive hoarseness was experienced by all patients and had been present from 2 to 60 months, with an average of 19.1 months. Three patients also complained of a husky voice, dysphagia, and changes in phonation. No patient had airway obstruction or presented acutely. On average, there was a shorter duration of symptoms for patients who had amyloid of the false vocal cord (12 months) than for patients who had masses in the true vocal cord alone (34 months) or for patients who had transglottic lesions (38 months). Four patients had evidence of multifocal disease, either at the time of initial presentation or shortly thereafter: three had laryngeal, tracheal, and bronchial tree disease, and the fourth had gastrointestinal disease. The other patients had a negative systemic workup, which included physical examination, laboratory tests, radiologic studies, and biopsies (bone marrow, rectal, or lip).

\section{Treatment and Patient Outcome}

All patients were treated initially with surgical excision of the amyloid mass/tumor, with recurrent masses excised as they were discovered. While stripping or laser therapy was used, specific surgical protocols were not available. No adjuvant therapy (radiation, chemotherapy, or immunotherapy) was used in any of the patients.

Follow-up information was available for all patients (Table 1). Eight patients were either alive $(n=$ 3 ; mean, 41.5 years after diagnosis) or dead of unrelated causes ( $n=5$; mean, 29.1 years after diagnosis) without evidence of disease (overall average, 33.8 years after diagnosis) at last follow-up. Six patients manifested either multifocal/systemic or recurrent disease-two patients (both light chain re-

TABLE 1. Patient Outcome and Average Survival

\begin{tabular}{|c|c|c|c|c|c|c|}
\hline \multirow{2}{*}{ Outcome } & \multicolumn{2}{|c|}{ All Patients } & \multicolumn{2}{|c|}{$\begin{array}{l}\text { Patients with Recurrent/Multifocal } \\
\text { Disease }(n=6)\end{array}$} & \multicolumn{2}{|c|}{$\begin{array}{l}\text { Patients with Light Chain } \\
\text { Restriction }(n=3)\end{array}$} \\
\hline & $n(\%)$ & $\begin{array}{c}\text { Average } \\
\text { Survival }(y)\end{array}$ & $n(\%)$ & $\begin{array}{c}\text { Average } \\
\text { Survival (y) }\end{array}$ & $n(\%)$ & $\begin{array}{c}\text { Average } \\
\text { Survival (y) }\end{array}$ \\
\hline Alive, NED & $3(27)$ & 41.5 & $1(16.7)$ & 43.4 & $0(0)$ & NA \\
\hline Alive, recurrent disease & $1(9)$ & 41.6 & $1(16.7)$ & 41.6 & $1(33.3)$ & 41.6 \\
\hline Dead, NED & $5(45)$ & 29.1 & $2(33.3)$ & 31.7 & $0(0)$ & NA \\
\hline Dead, with disease & $2(9)$ & 11.1 & $2(33.3)$ & 11.1 & $2(66.7)$ & 11.1 \\
\hline
\end{tabular}

NED, no evidence of disease; NA, not applicable. 
stricted) were dead with recurrent disease, although not dead of disease (one of whom had multifocal disease) (mean, 11.1 years); two patients were dead with no evidence of disease (NED) (both with multifocal disease, one had a single recurrence; mean, 31.7 years); and two patients were alive at last follow-up. Of the last two, one had recurrent and multifocal disease (light chain restricted; 41.6 years), and the other is alive with NED (43.4 years) after a single recurrence at 7 years after the initial presentation. The patients who developed recurrent disease tended to have polypoid rather than granular and diffuse amyloid deposits. In summary, the three patients who demonstrated evidence of immunohistochemical light chain restriction all had evidence of disease at last follow-up (one is alive and two are dead). No patient developed multiple myeloma or an overt B-cell malignancy.

\section{Pathologic Findings}

\section{Macroscopic pathology}

Amyloid occupied a transglottic location $(n=6)$, involved the true vocal cord alone $(n=4)$, or involved the false vocal cord alone $(n=1)$ (Table 2$)$. There was extension into the subglottic region in two of the transglottic cases. Five cases occurred bilaterally, and the remaining six were unilateral, divided equally between the right and left sides. Vocal cord mobility was not impaired in any of our cases. The lesions were described as elevated, smooth to bosselated, polypoid ( $n=5)$, mucosacovered, firm masses in the transglottic region. The lesions were more generalized, diffuse to granular, waxy swellings in the supraglottic and subglottic region $(n=6)$. No surface ulceration was noted. The cut surface reflected the derivation of amyloid [meaning "starch-like" $(21,22)]$ and was firm, pale, waxy, homogeneous, and translucent-appearing and ranged from tan-yellow to red-gray. The masses ranged in size from 0.4 to $3.4 \mathrm{~cm}$ in maxi-

TABLE 2. Macroscopic Findings

\begin{tabular}{lc}
\hline & $\begin{array}{c}\text { Laryngeal } \\
\text { Amyloid }\end{array}$ \\
\hline Anatomic location & 4 \\
True vocal cord & 1 \\
False vocal cord & 1 \\
False cord and subglottis & 4 \\
True and false cord & 1 \\
True cord and subglottis & 5 \\
Bilateral & 3 \\
Right & 3 \\
Left & \\
Size & $0.4-3.4 \mathrm{~cm}$ \\
Range & $1.6 \mathrm{~cm}$ \\
Average & 5 \\
Macroscopic appearance & 6 \\
Polypoid mass & \\
Granular, waxy & \\
\hline
\end{tabular}

mum dimension, with an average size of $1.6 \mathrm{~cm}$. The transglottic lesions were larger on average $(1.8 \mathrm{~cm})$ than masses of the true vocal cord alone $(1.0 \mathrm{~cm})$ but were not as large as the mass of the false cord $(2.8 \mathrm{~cm})$.

\section{Microscopic pathology}

The amyloid presented as subepithelial, extracellular, acellular, amorphous, eosinophilic material (Fig. 1). In none of our cases was the amyloid difficult to identify. It was dispersed randomly throughout the lamina propria, sparing the overlying epithelium, and frequently demonstrated a perivascular (Fig. 2A) and periglandular (Fig. 2B) deposition, sometimes completely obliterating the seromucous glands by compression atrophy. A sparse inflammatory infiltrate noted in all cases was composed of lymphocytes and plasma cells with occasional histiocytes and a few giant cells, either at the peripheral margin of or enclosed within the amyloid (Fig. 3). Significant cytologic atypia of the lymphoplasmacytic infiltrate was not identified. The foreign body-type giant cells were arranged focally around the periphery of the amyloid deposits in five cases.

\section{Special techniques}

Amyloid was confirmed with histochemical techniques (Congo red, methyl violet). Apple-green birefringence under polarized light with Congo red (Fig. 4) proved to be the most reliable and easy-tointerpret technique. Although CD20 and CD3 highlighted B cells and T cells in the sparse lymphoplasmacytic infiltrate, respectively, T cells tended to predominate, especially in the periphery of the amyloid deposits. Immunohistochemical analysis demonstrated light chain restriction of the plasma cells in 3 of 10 cases analyzed ( $\kappa=2, \lambda=1)$ (Fig. 5 ).

\section{DISCUSSION}

The term amyloid encompasses a family of different types of extracellular, fibrillar protein depos-

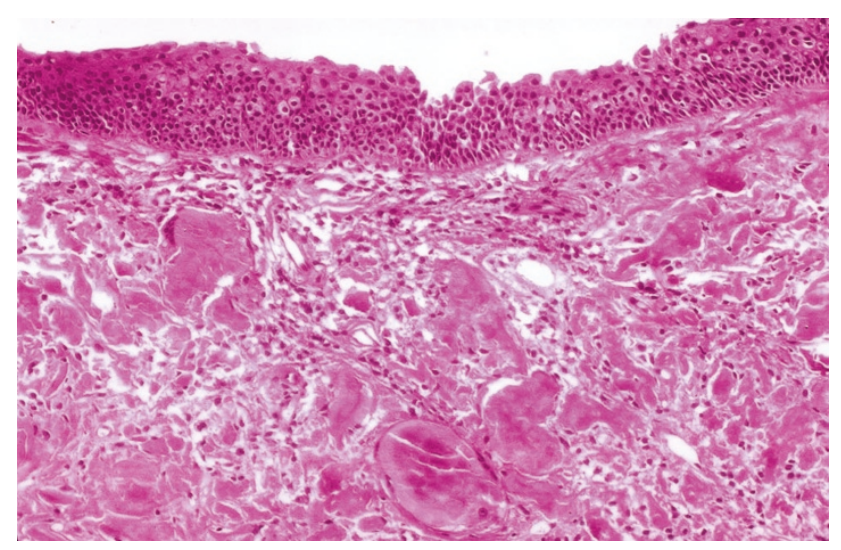

FIGURE 1. Amyloid deposition in the lamina propria, sparing the overlying epithelium. 

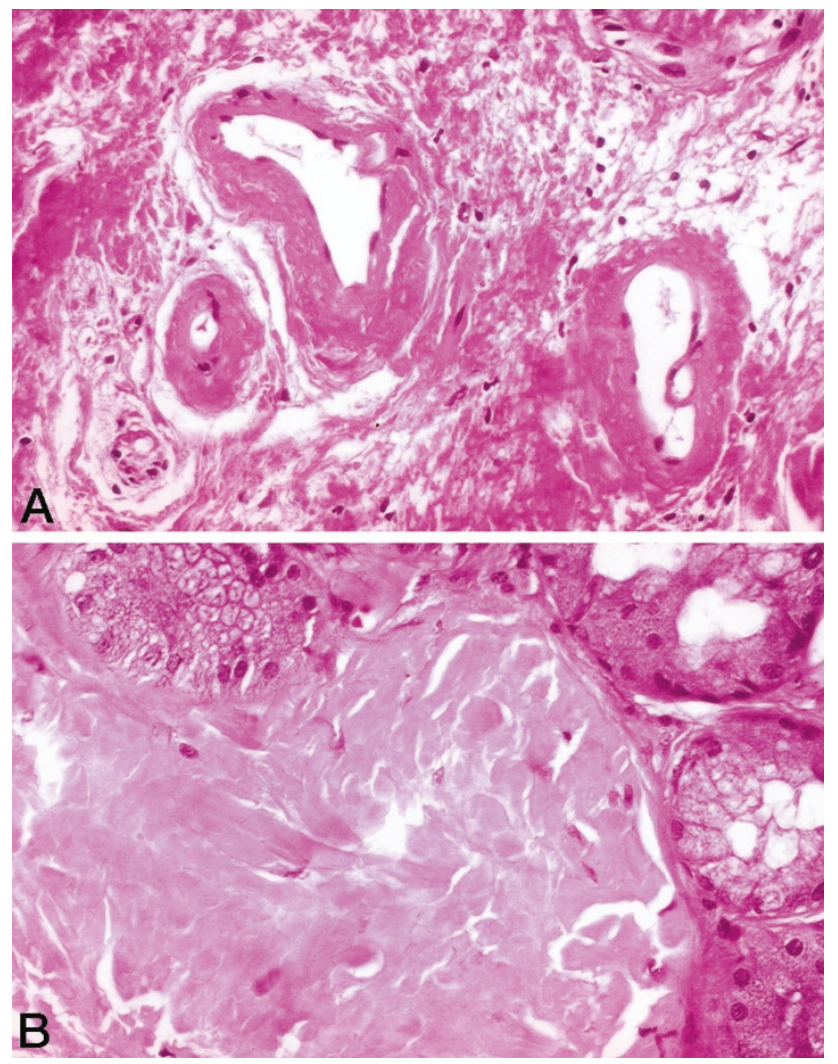

FIGURE 2. A, perivascular deposition of amyloid in the subepithelial region. B, a periglandular deposition of amyloid.

its. The literature supports that most cases of amyloidosis of the larynx are composed of a protein that is immunologically identical to the variable region of the light chain fragment of immunoglobulin (1, $7-9,16,17,23,24)$ and is classified as a fibril type, similar, if not identical, to that of primary amyloid $(2,3,5,7,16,24-27) . \lambda$ has been reported with greater frequency, perhaps because $\lambda$ light chains have a $\beta$-pleated configuration similar to amyloid $(5,6,8,16)$. Although immunophenotyping has become universally available, the "gold standard" for the diagnosis of amyloid remains a tissue biopsy demonstrating characteristic hematoxylin and eosin changes and Congo red birefringence or metachromatic pink-violet staining with methyl violet or crystal violet.

The immunoglobulin nature of laryngeal amyloid is accepted, but the source of the immunoglobulin is unclear. The lesion may develop from a localized monoclonal immunoproliferative disorder, in which the plasma cells, which are intimately associated with the amyloid deposits, are thought to produce the light chain immunoglobulin that is deposited as amyloid, rather than represent an inflammatory infiltrate reacting to the deposited amyloid (1, 3, 5, 9, 17, 24, 28-30). This intimate association of the lymphoplasmacytic infiltration is different from systemic amyloidosis whereby the plasma cells are spatially separated from the amy-
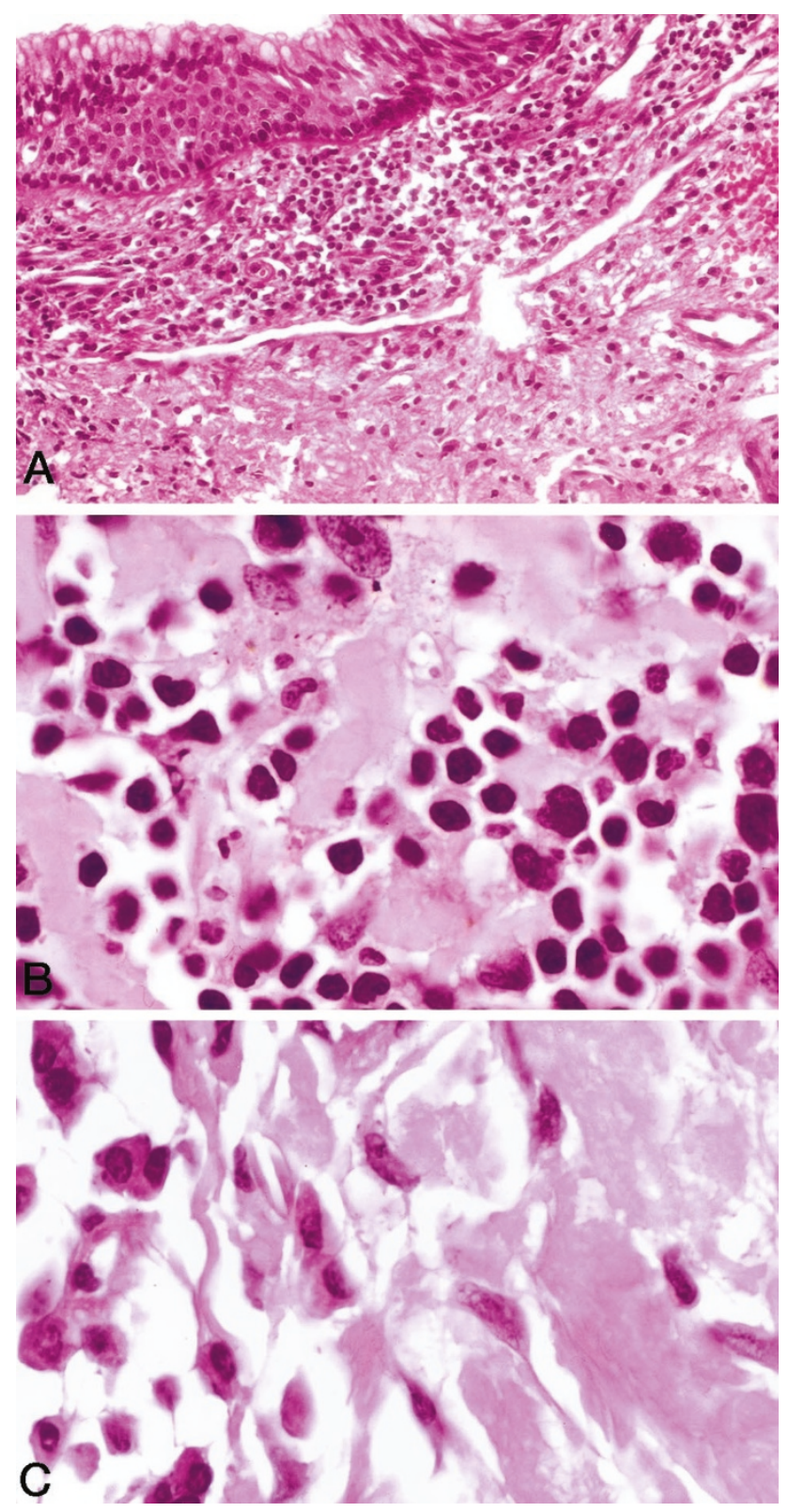

FIGURE 3. A, subepithelial lymphoplasmacytic infiltrate near an area of amyloid deposition. B, lymphoplasmacytic infiltrate between deposits of amyloid. C, infiltrate of mature plasma cells at the edge of an amyloid deposit.

loid deposition $(2-4,7,9,17,24,26,30)$. Many LA cases in the literature have been associated with immunostaining for light chain restriction of both the plasma cells and the amyloid $(1,8,16,17)$.

The second theory for the amyloid deposition suggests that a circulating precursor protein is deposited in the stroma after a change in the vascular permeability as a result of local inflammation $(2,9$, $25,26,30)$. The plasma cells may be either inciting the inflammation or reacting to the amyloid. There are an insufficient number of cases to implicate chronic inflammation and/or an infectious agent as the cause of organ-specific amyloidosis (1, 9, 25, 30). In an individual case, the possibility of a circu- 


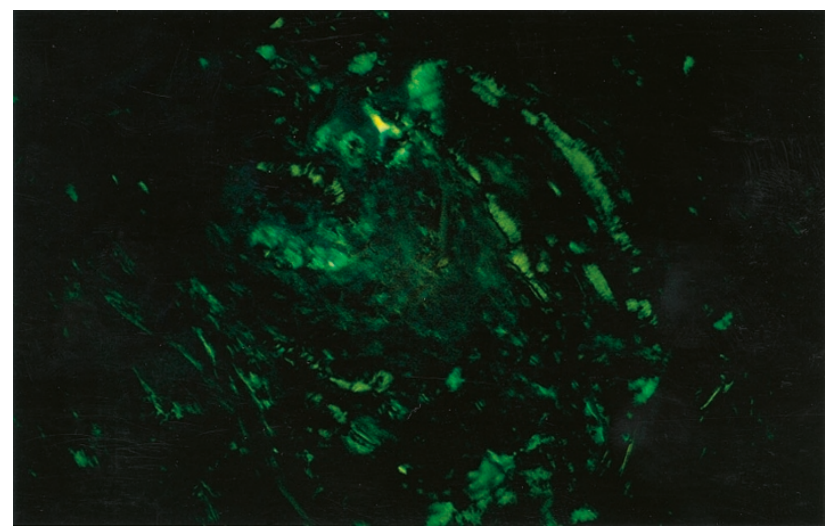

FIGURE 4. Amyloid demonstrating apple-green birefringence with polarized light with Congo red.

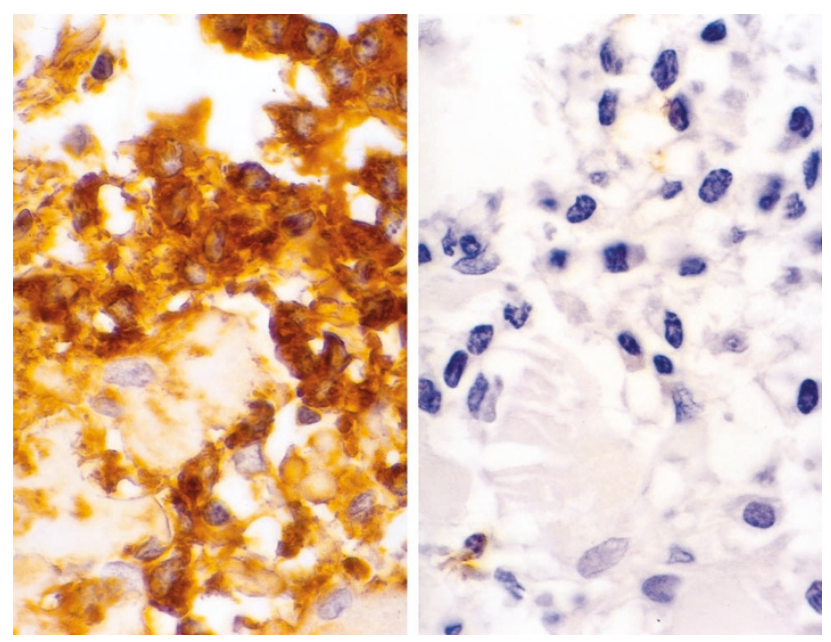

FIGURE 5. Staining of the lymphoplasmacytic infiltrate for $\kappa$ (left) and $\lambda$ (right), demonstrates $\kappa$ light chain restriction.

lating immunoglobulin protein or a variable portion of a light chain as the source of the amyloid fibrils of immunoglobulin origin must still be considered, even though it seems more likely that it is formed from the contiguous plasmacytic infiltrate (26).

There have been a variety of classifications of amyloidosis: according to its distribution (localization), clinical type, and the presence or absence of underlying disease and by its precursor protein (immunocytochemical nature) and patterns of extracellular deposition $(1-3,6,8-11,19,27,31-33)$. A modification of these classification schemes is presented in Table 3 . The three forms of systemic amyloidosis include the primary form, the reactive form, and the familial form. The localized form is rare, with the larynx affected more frequently than any other single site $(1,3,7,8,12,13)$. Needless to say, although a patient may fit into one of these classes initially, close follow-up is required to rule out the presence of amyloid deposits in other organs. On the basis of our findings and those of the literature $(1,6,8,9,11-13,19,26,30,34)$, it seems that most cases develop as primary amyloidosis (focal), but may occasionally be part of systemic primary amyloidosis.

Almost all patients experience hoarseness or voice changes, usually caused by mechanical factors, conditioned by the size and location of the amyloid. They usually present as adults $(1,7,8,10$, $13,17,19,31,35,36)$ and, in our series, with a mean age of 37.8 years. Although none of our cases were children, case reports in pediatric patients are documented $(8,12,13,16,18,19,36-38)$. The average age of patients in our series who developed recurrence or had multifocal disease was older (45.2 years) than patients who did not develop recurrence (37.2 years), although we do not have an explanation for this finding. Although various investigators have demonstrated either a male or a female predominance, we found a male predominance in our series $(1,6-8,10-16,19,23,25,27,29$, $31,35-38)$.

TABLE 3. Modified Classification of Amyloidosis (2, 3, 6, 8, 9, 11, 15, 16, 26, 27)

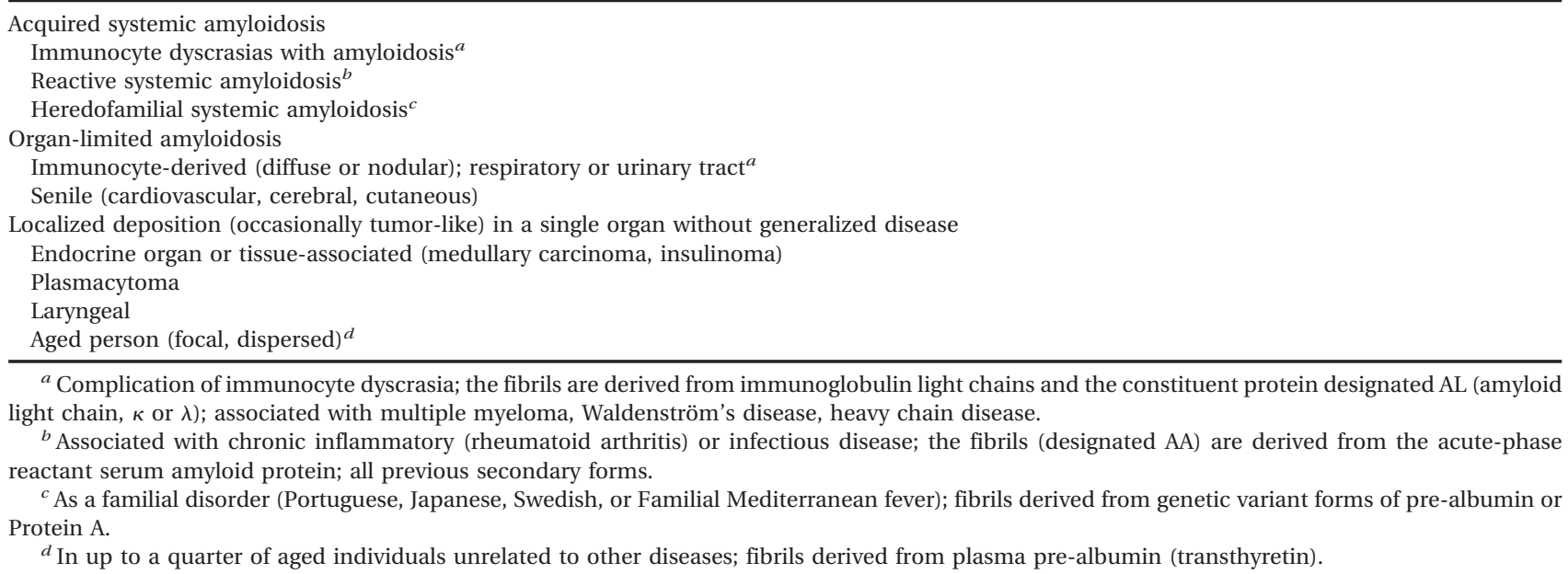


There does not seem to be a specific location in the larynx that is more frequently affected by amyloidosis; instead, all parts of the larynx can be affected $(1,7,8,10,13,14,16,17,19,23,34-37,39)$. LA deposition is usually a localized disease but can be part of multifocal and/or systemic disease or secondary to an underlying disease or tumor proliferation $(2,4,7-10,13-15,23,30)$. Multifocal disease was noted in the upper aerodigestive tract in three of our patients. Amyloidosis of the stomach was noted in one of our patients 10 years after the initial presentation of laryngeal disease. Many cases reported in the English literature also document multifocal or systemic amyloidosis (1, 4, 7-10, 14, $30,40)$, but only rarely was a true B-cell neoplasm documented $(1,40)$. None of our cases had documented serum or urine electrophoretic abnormalities, and none of our patients developed multiple myeloma or an overt B-cell malignancy. Although a plasma cell dyscrasia could not be documented in any of our cases, an associated monoclonal B-cell proliferation was present. Furthermore, the three patients who developed recurrent disease and who also demonstrated multifocal disease, demonstrated light chain restriction by immunohistochemical studies. Therefore, in view of the mucosal presentation of LA, the recurrence and multifocal presentation in other mucosal sites, the monoclonal nature of the associated lymphoplasmacytic infiltrate in three cases, and a lack of systemic plasma cell dyscrasias in all of our cases, we believe that at least a few LA cases may be the result of an immunocyte dyscrasia or lymphoproliferative disorder with an origin from mucosa-associated lymphoid tissue (MALT) (1, 4, 6, 7, 17, 29, 40). In fact, MALT lymphoma has been associated with amyloid deposition in other anatomic sites (41-44).

There is a difference in the biologic behavior and clinical management between isolated LA and secondary amyloidosis, extramedullary plasmacytoma, multiple myeloma, and neuroendocrine carcinoma, in which amyloid deposition can occur. A wide variety of studies have suggested separating laryngeal amyloid from these other conditions. A clinical and laboratory assessment, including a search for lymphadenopathy, radiographic imaging (chest $\mathrm{x}$-ray, skeletal survey, urinary and digestive tract evaluation), electrocardiogram, peripheral blood smear examination, complete blood count, bone marrow biopsy, tissue assessment for systemic amyloid, and clinical laboratory studies (erythrocyte sedimentation rate, liver chemistries, renal function studies, quantitative immunoglobulin assay, serological test for rheumatoid arthritis, urine analysis, urine and/or serum electrophoresis, Bence-Jones protein analysis) has been suggested to ascertain the true nature of the process $(1,7,14$, 17-19, 25, 35). Furthermore, as indicated clinically, a rectal, lip, gum, kidney, spleen, liver, endomyocardial, skin, or small-bowel biopsy and/or abdominal fat aspirate may be performed to exclude systemic disease. An endoscopic examination of the aerodigestive tract may be necessary, given the high incidence of multifocal involvement by the disease $(1,3,8,9,17,19,25,27)$. As noted, none of our patients demonstrated evidence of lymphadenopathy, multiple myeloma, or an overt B-cell neoplasm. However, stomach amyloidosis was documented in a single patient, along with the development of multifocal disease within the upper respiratory tract, trachea, and main bronchi of three patients. The airway disease was documented within a short time of the initial laryngeal presentation and so may be part of multifocal disease at the time of initial presentation. Therefore, although it may not be necessary to perform the entire gamut of investigative studies in each individual patient, a tailoring of these radiographic, laboratory, and invasive procedures to each individual patient to exclude systemic disease is suggested.

Other diseases can also be associated with amyloid in the larynx, including small cell carcinoma of the larynx or a medullary carcinoma of the thyroid that has invaded the larynx. This diagnostic differential usually can be assessed with the application of immunohistochemical antibodies for keratin, chromogranin, calcitonin, or other neuroendocrine markers. The determination of a serum calcitonin level can help to distinguish between a primary laryngeal tumor (serum elevation absent) versus a metastatic/invasive tumor from the thyroid gland (serum elevation present). A number of other disorders are included in the differential diagnosis of LA. Ligneous conjunctivitis, a hereditary or familial disease, presents as pseudomembranous-covered, fibrous, woody, plaque-like deposits in the larynx or trachea of accumulated acid mucopolysaccharides and hyaluronic acid surrounded by inflammatory cells and vessels. These deposits are negative for amyloid stains and present with a different clinical picture (45). Lipoid proteinosis (hyalinosis cutis et mucosae) may have a similar clinical appearance to amyloid but tends to have a more widespread extracellular deposition of amorphous hyaline lipoproteins (neutral and acid mucopolysaccharides) in the skin and mucous membranes. They are negative for amyloid stains (46). Hyalinized-type vocal cord nodules or polyps usually lack an associated lymphoplasmacytic infiltrate (if present, it is not usually at the periphery of the lesion) and are usually negative for methyl violet and Congo red (13, 23).

LA seems to be an indolent process, with patients living a long time with evidence of recurrent disease. Even patients who died with disease were alive for more than 10 years after their initial pre- 
sentation. Therefore, it is important to have sustained and regular long-term follow-up of these patients to assess accurately the disease progression, using conservative clinical management to preserve laryngeal function for as long as possible $(1,6-8,13,14,16,19,23,25,37,40)$.

In summary, LA is an uncommon disorder that usually represents a form of localized amyloidosis. However, LA may occasionally be associated with multifocal and/or systemic disease. No specific laryngeal anatomic site seems predisposed to amyloid deposition (supraglottic or vocal cord). Recurrent and/or persistent laryngeal disease is common. Some LA cases may represent immunocyte dyscrasias of MALT, and evidence of an associated monoclonal lymphoid process may portend a worse clinical outcome. Conservative surgical intervention to maintain laryngeal function for as long as possible and long-term clinical follow-up to disclose recurrent/residual disease are suggested. Although the possibility of systemic disease is low, appropriate clinical, radiographic, and laboratory investigation to rule out systemic disease and to subclassify correctly the form of amyloidosis is recommended.

\section{Acknowledgments: The authors thank Anthony Shirley for his expert photography.}

\section{REFERENCES}

1. Chen KTK. Amyloidosis presenting in the respiratory tract. Pathol Ann 1989;24:253-73.

2. Glenner GG. Amyloid deposits and amyloidosis. The $\beta$-fibrilloses (first of two parts). N Engl J Med 1980;302:128392.

3. Glenner GG. Amyloid deposits and amyloidosis. The $\beta$-fibrilloses (second of two parts). N Engl J Med 1980;302: 1333-43.

4. Grogan TM, Spier CM. The B cell immunoproliferative disorders, including multiple myeloma and amyloidosis. In: Knowles D, editor. Neoplastic hematopathology. Philadelphia: W.B. Saunders; 1992. p. 1235-60.

5. Horita S, Nitta K, Honda K, Yumura W, Nihei H. A simple histological method differentiating AL-type from AA-type amyloidosis. Nephron 1998;78:240-2.

6. Kyle RA, Bayrd ED. Amyloidosis: review of 236 cases. Medicine 1975;54:271-99.

7. Lewis JE, Olsen KD, Kurtin PJ, Kyle RA. Laryngeal amyloidosis: a clinicopathologic and immunohistochemical review. Otolaryngol Head Neck Surg 1992;106:372-7.

8. O'Halloran LR, Lusk RP. Amyloidosis of the larynx in a child. Ann Otol Rhinol Laryngol 1994;103:590-4.

9. Symmers WSC. Primary amyloidosis: a review. J Clin Pathol 1956;9:187-211.

10. Stark DB, New GB. Amyloid tumors of the larynx, trachea or bronchi. A report of 15 cases. Ann Otolaryngol 1949;58:11734 .

11. Holinger PH, Johnston KC, Delgado A. Amyloid tumors of the larynx and trachea. Arch Otolaryngol 1959;70:555-61.

12. McAlpine JC, Radcliffe A, Fuller AP. Primary amyloidosis of the upper air passages. J Laryngol 1963;77:1-28.

13. McAlpine JC, Fuller AP. Localized laryngeal amyloidosis, a report of a case with a review of the literature. J Laryngol Otol 1964;78:296-314.

14. Hellquist H, Olofsson J, Sökjer H, Ödkvist LM. Amyloidosis of the larynx. Acta Otolaryngol 1979;88:443-50.

15. Bennett JDC, Chowdhury CR. Primary amyloidosis of the larynx. J Laryngol Otol 1994;108:339-40.

16. Godbersen GS, Leh JF, Hansmann ML, Rudert R, Linke RP. Organ-limited laryngeal amyloid deposits: clinical, morphological, and immunohistochemical results of five cases. Ann Otol Rhinol Laryngol 1992;101:770-5.

17. Berg AM, Troxler RF, Grillone G, Kasznica J, Kane K, Cohen AS, et al. Localized amyloidosis of the larynx: evidence for light chain composition. Ann Otol Rhinol Laryngol 1993;102: 884-9.

18. Ryan RE Jr, Pearson BW, Weiland LH. Laryngeal amyloidosis. ORL Otorhinolaryngol Relat Spec 1977;84:872-7.

19. Graamans K, Lubsen H. Clinical implications of laryngeal amyloidosis. J Laryngol Otol 1985;99:617-23.

20. Hsu SM, Raine L, Fanger H. Use of avidin-biotin-peroxidase complex $(\mathrm{ABC})$ in immunoperoxidase techniques: a comparison between $\mathrm{ABC}$ and unlabeled antibody (PAP) procedures. J Histochem Cytochem 1981;29:577-80.

21. Virchow RLK. Weitere Mitteilungen uber das Vorkommen der pflanzlichen cellulose beim Menschen. Arch Pathol Anat 1954;6:268-78.

22. Rokitansky KFV. Hanbuch der speciellen pathologischen anatomie. Vol. 2. Vienna, Germany: Braunumüller \& Siedel; 1842.

23. Michaels L, Hyams VJ. Amyloid in localised deposits and plasmacytomas of the respiratory tract. J Pathol 1978;128: 29-38.

24. Osserman EF. Plasma-cell myeloma. II. Clinical aspects. N Engl J Med 1959;261:1006-14.

25. Finn DG, Farmer JC Jr. Management of amyloidosis of the larynx and trachea. Arch Otolaryngol 1982;108:54-6.

26. Glenner GG, Terry WD, Isersky C. Amyloidosis: its nature and pathogenesis. Semin Hematol 1973;10:65-86.

27. Kyle RA, Greipp PR. Amyloidosis (AL). Clinical and laboratory features in 229 cases. Mayo Clin Proc 1983;58:665-83.

28. Cohen AS. Medical progress: amyloidosis. N Engl J Med 1967;277:522-38.

29. Ferrara G, Boscaino A. Nodular amyloidosis of the larynx. Pathologica 1995;87:94-6.

30. Rodriguez-Romero R, Vargas-Serrano B, Cortina-Moreno B, Fernández-Gallardo JM, Cervera-Rodilla JL. Calcific amyloidoma of the larynx. AJNR Am J Neuroradiol 1996;17:1491-3.

31. McCall JW, Fisher WR. Primary amyloidosis of the larynx with a report of experimental treatment with cortisone. Ann Otol Rhinol Laryngol 1962;72:316-28.

32. New GB. Amyloidosis. Laryngoscope 1919;29:327-37.

33. Barnes EL Jr, Zafar T. Laryngeal amyloidosis. Clinicopathologic study of seven cases. Ann Otolaryngol 1977;86:856-63.

34. Creston JE. The otolaryngologic manifestations of multiple myeloma. Laryngoscope 1978;88:1320-32.

35. D'Arcy F. Localized amyloidosis of the larynx. J Laryngol Otol 1972;86:929-31.

36. Mitrani M, Biller HF. Laryngeal amyloidosis. Laryngoscope 1985;95:1346-7.

37. Heinritz H, Kraus T, Iro H. Localized amyloidosis in the head and neck. A retrospective study. HNO 1994;42:744-9.

38. Hurbis CG, Holinger LD. Laryngeal amyloidosis in a child. Ann Otol Rhinol Laryngol 1990;99:105-7.

39. Hardingham M. Diffuse amyloidosis of the larynx. Ear Nose Throat J 1987;66:32-8.

40. Talbot AR. Laryngeal amyloidosis. J Laryngol Otol 1990;104: 147-9.

41. Caulet S, Robert I, Bardaxoglou E, Noret P, Tas P, Le Prise Y, et al. Malignant lymphoma of mucosa associated lymphoid 
tissue: a new etiology of amyloidosis. Pathol Res Pract 1995; 191:1203-7.

42. Odell EW, Lombardi T, Shirlaw PJ, White CA. Minor salivary gland hyalinisation and amyloidosis in low-grade lymphoma of MALT. J Oral Pathol Med 1998;27:229-32.

43. Wilk W, Papla B. Amyloidoma and marginal zone malignant lymphoma (MALT type) in the gastric antrum. A case report. Pol J Pathol 1998;49:183-6.
44. Ferrara G, Boscaino A. Nodular amyloidosis of the larynx. Pathologica 1995;87:94-6.

45. Cohen SR. Ligneous conjunctivitis: an ophthalmic disease with potentially fatal tracheobronchial obstruction. Laryngeal and tracheobronchial features. Ann Otol Rhinol Laryngol 1990;90:509-18.

46. Richards SH, Bull PD. Lipoid proteinosis of the larynx. J Laryngol Otol 1973;87:187-90. 